\title{
Artelogie
}

Recherche sur les arts, le patrimoine et la littérature de l'Amérique latine

$11 \mid 2017$

Délocalités, translocalités et activisme dans l'art électronique et biomédiale latino-américain

\section{Prácticas co-creativas. Decolonizar la naturaleza}

\section{Mariela Yeregui}

\section{OpenEdition}

Journals

Edición electrónica

URL: http://journals.openedition.org/artelogie/1601

DOI: 10.4000/artelogie.1601

ISSN: 2115-6395

Editor

Association ESCAL

Referencia electrónica

Mariela Yeregui, « Prácticas co-creativas. Decolonizar la naturaleza », Artelogie [En línea], 11 | 2017,

Publicado el 28 diciembre 2017, consultado el 19 abril 2019. URL : http://journals.openedition.org/ artelogie/1601 ; DOI : 10.4000/artelogie.1601

Este documento fue generado automáticamente el 19 abril 2019.

Association ESCAL 


\title{
Prácticas co-creativas. Decolonizar la naturaleza
}

\author{
Mariela Yeregui
}

\section{Arte y territorio}

"Como los antiguos navegantes cuando se aproximaban a una tierra desconocida, examinamos, observamos los menores detalles que pueden indicar un cambio" (DARWIN, 2008: 45)

1 La expedición exploratoria del territorio sudamericano llevada a cabo por Charles Darwin en 1832, además de recolectar, catalogar y describir exóticos animales y restos fósiles, debía restituir a Jemmy Button, el joven yagán que había sido capturado años antes durante la expedición de Fitz Roy a esos confines.

2 La historia de Jemmy es paradójica y emblemática. Condensa, de manera simbólica, el imaginario del colonizador. Pero, sobre todo, cristaliza -y esto es aún más rotundo y lapidario- la relación de fuerzas entre unos y otros.

3 En aquella expedición previa de 1830, el trato fue simple: tan solo un botón por aquel robusto y jovial hombre quien, a partir de esa transacción, pasó a ser llamado Jemmy Button por sus captores. Un acto de nominalización que, en definitiva, no hace sino instaurar el trauma social, según Butleri.

4 En Inglaterra, el joven yagán gozó de cierta popularidad. El propio rey Guillermo lo recibió en encuentros privados. La extrañeza ante el Otro podría ser un detalle del orden del pintoresquismo anecdótico si no fuera porque revela también configuraciones territoriales en términos amplios: territorios culturales, ideológicos y geopolíticos. El territorio es así una superficie de contraste donde la noción de "otredad" adquiere una relevancia extrema. El sujeto yagán no habría sido un Otro si no fuera porque sufrió un proceso de desterritorialización (geográfica, nominalizadora, cultural, etc.).

El discurso de la modernidad se construye desde la propia ipseidad. El Otro -el nomoderno, bajo el espejismo de devenir moderno, o mejor, un bárbaro "civilizable"- no entra en el proyecto moderno más que como condición de posibilidad. Se es moderno en 
relación al no-moderno (lo no-occidental). Porque para la modernidad, el Otro no es más que Otro sólo si permite la definición del Mismo. En otras palabras, la definición de la modernidad es posible en función de la presencia de lo no-moderno (lo no-occidental) en su propio estrato de formulación. Ahora bien, contraparte necesaria para tejer los andamiajes del Mismo, la modernidad en América Latina implica la dupla modernidad/ colonialidad, en tanto cesura diferencial que abre paso a la labor "civilizadora" de Occidente.

6 La modernidad se define en y por la colonialidad, siendo ésta última un patrón de poder que modela un esquema de acción y un marco de pensamiento. A diferencia del colonialismo que refiere a un proceso histórico de dominación y de ejercicio del poder, apoyado en una estructura institucional, militar y religiosa, la colonialidad, en tanto proceso, en cambio, excede al régimen colonial.

7 En este punto, es esencial desterrar la mirada histórico-lineali ${ }^{\mathrm{ii}} \mathrm{y}$ retomar el concepto de "sistema-mundo" introducido por el sociólogo Immanuel Wallerstein, quien lo define como un sistema global de desigualdades estructurales. El sistema -mundo es una unidad de análisis que excede a los estados-nación o a los regionalismos y que aborda a la dinámica de la colonialidad como sistema mundializado de poder, en el que las diferentes experiencias regionales responden a lógicas y mecanismos a escala planetaria. Este sistema-mundo responde a tres fenómenos: el capitalismo como sistema económico economía-mundo en la que América se incorpora a los flujos relacionales de Europa-AsiaÁfrica-, el auge de la ciencia y de la tecnología, la secularización de la vida social, la estandarización como resultado del auge del estado y la pretensión de universalidad (cultural, epistemológica, discursiva, etc.).

8 La modernidad emergería así de este complejo entramado de relaciones en el que la colonialidad termina por cristalizarla y cohesionarla, no tanto en su dimensión histórica, sino más bien en su sustrato ideológico. "[...] no hay modernidad sin colonialidad [...]" (Mignolo 2003: 34).

9 Esta digresión inicial no es caprichosa. Es esencial para entender desde qué punto de vista propongo examinar las producciones artísticas tecnológicas producidas en el contexto latinoamericano y, más específicamente, aquellas que articulan dinámicas, discursos, retóricas y lenguajes que se adhieren e interpelan a la naturaleza y a la tecnología. Desde una mirada decolonial -esta suerte de bisagra epistemológica-, propongo repensar aquellos enfoques fuertemente teñidos de miradas euro u occidentocéntricas.

10 El territorio de las modernidades periféricas asume configuraciones diferenciales. Esta territorialidad emerge en los trabajos de algunos artistas tecnológicos latinoamericanos de manera neta y con un vigor expresivo -que señaliza y enfatiza la emergencia de otro, desafiando ciertos postulados medulares de la modernidad. El antropocentrismo, cimiento de la visión moderna, es desmantelado así y relegado hacia otras latitudes.

11 Lo que subyace en esta relación Uno-Otro basada en mecanismos de subsunción, es la emergencia de procesos de territorialización. Definir territorios supone agenciamientos sociales que forjan marcos espaciales, culturales y sociales. La relación arte-tecnología moldea territorios en los que estas mecánicas de alteridad asumen rasgos pregnantes y aspectos diferenciales en escenarios donde el Otro se asume como sujeto productor. En los territorios en los que se subvierte el horizonte expectatorial del sujeto hegemónico / Otro-consumidor-tecnológico, éste último pasa a ser un sujeto activo en la conceptualización de las tecnologías, poniendo en evidencia operaciones que entrañan 
universos críticos. Muchas de las prácticas tecno-artísticas desarrolladas en el contexto de Latinoamérica son el disparador y el fusible para una experiencia de imbricación y exploración con tecnologías y lenguajes portadores de capitales semánticos fuertemente arraigados en espacios centrales de la discursividad tecno-científica. En este contexto, la conflictividad no hace sino emerger con gran potencia.

Por eso, y a fin de visibilizarlo de manera enfática aventuro una idea que puede parecer polémica y precipitada a simple vista pero que sirve, en definitiva, para poner en crisis ciertas ideas dominantes: la relación arte / tecnología en algunas experiencias en Argentina engendra discursividades que decolonializan presupuestos hegemónicos en lo que respecta a las miradas en torno a la naturaleza y a las prácticas tecnológicas

Se trataría de desarmar entonces el andamiaje ideológico y la arquitectura conceptual, vehiculizados por los presupuestos que sostienen la tríada arte-naturaleza-tecnología, en el campo de las prácticas artísticas que se desarrollan en el contexto argentino.

En el recorte que opero, los territorios artísticos están atravesados por un determinado concepto de naturaleza y por discursos y retóricas que ponen en crisis ciertos paradigmas homogeneizantes en torno a los usos creativos de la tecnología. Pero antes de adentrarme en esta pervasividad tecnológica de la que tanto se ha hablado y teorizado, hay una pregunta que creo conveniente formular: ¿cómo se produce el diálogo arte-naturalezaterritorio en el escenario actual argentino?

\section{Bioarte o como sea que debiera llamarse}

15 La relación hombre-naturaleza ha sido extensamente abordada en el último tiempo en el campo de cruce arte-tecnología. Bajo el paraguas conceptual del término "bioarte" se alojan estrategias, prácticas e ideologías por demás diversas. Para Daniel López del Rincón (2015) habría dos tendencias marcadas, diferenciadas por su componente medial. El autor denomina a la primera "biotemática" y es la que alude a tópicos biotecnológicos a través de medios tradicionales. La "biomedial", en cambio, se opone a la anterior, a la que achaca aproximarse externamente a la biotecnología. "La tendencia biomedial del bioarte se plantea como el rebasamiento de una frontera que la tendencia biomediática sí respetaba: la que separa arte y vida" (LÓPEZ DEL RINCÓN 2015: 21).

El exhaustivo análisis de López Rincón reposa muy fuerte y claramente sobre definiciones del espacio arte-naturaleza que derivan de asumir la medialidad biológica como rasgo fundante. Así, el artista que opera desde la corriente biotecnológica desarrolla prácticas que dialogan con una medialidad científica, según el autor -medialidad ésta que no sólo alude a la materialidad constructiva específica sino también a los medios de investigación utilizados en el proceso creativo. El dispositivo científico funciona así como una suerte de metatexto epistemológico sobre el que reposa la retórica biomedial. La noción de "laboratorio" opera, de este modo, como condición de base para la producción artística, fundada en tres aspectos: a) el espacio-laboratorio se convierte en espacio-taller; b) el laboratorio como proveedor de técnicas y materiales para el artista; c) el activismo biológico que rechaza la vinculación con el laboratorio y sus metodologías, propulsando "la vocación contestaría y contextual, la concepción metacrítica de los espacios (laboratorios) y los medios (técnicas, tecnologías, habilidades) utilizados por los bioartistas y la reivindicación de un amateurismo científico" (ibid.: 29). Lo cierto es que las tres modalidades, a pesar de accionar a partir de estrategias diferentes, se emparentan 
por el uso de materiales vivos, por un lado, y accionan desde los paradigmas modernos de la ciencia -ya sea por confirmación o por confrontación-, por el otro. Ninguna de ellas tampoco puede escapar a la lógica del "laboratorio" -tanto desde una mirada confirmatoria o desde una posición crítica. Como señala Dumit (2008) "no hay espacio por fuera del laboratorio, ningún espacio que no sea familiar al laboratorio y ninguna fracción de tiempo que no sea de regulación e invención social, política y artística" iii.

Ahora bien, si el conjunto de obras que utilizan la materia viva ha tenido un rol protagónico en la escena del arte tecnológico de los últimos años, la perspectiva creativa -y también crítica- a la hora de abordar el binomio arte/biología, ha sido la de focalizar en aquellas manifestaciones centradas en la preponderancia creativa del sujeto. En el campo del arte tecnológico latinoamericano, sin embargo, se vislumbran otras prácticas que, muy enfáticamente, echan por tierra toda pretensión antropocentrista y van más allá de la interpelación y/o crítica de las prácticas científicas. Tal vez más próximos a la tercera de las corrientes identificadas por López Rincón, particularmente en lo que respecta a la vocación contextual y a la desatención de los mandatos científicos, ciertos ("ciertas" debiera decir en función del recorte que efectúo) artistas desbaratan cualquier posibilidad de "jemmybuttonización", al asentar sus prácticas (artísticas y de pensamiento) sobre "discursividades-otras" en relación a las retóricas tecnológicas dominantes. Ya no serían las acciones bioartísticas las que desencadenarían procesos biotecnológicos, sino el embebimiento del sujeto creador en una naturaleza que opera como paisaje -y no como instancia externa a la cual abordar, interrogar o inspeccionar desde prácticas y dispositivos antropocéntricos legitimantes de la ciencia o, incluso, desde perspectivas críticas que, sin embargo, no logran superar el hiato humano/ naturaleza. Estas prácticas y acciones que abordaré se acomodan con dificultad a lo que habitualmente se denomina bioarte. Más allá de cuestiones terminológicas, lo que me impulsa a referir a ciertas experiencias que se han venido dando en el contexto argentino, es pensar algunos territorios que emergen con fuerza autonómica y que plantean diálogos fecundos con prácticas más consolidadas y legitimadas en el panorama internacional del arte y la tecnología, delineando, quizás, territorios diferenciales.

\section{Reterritorialización de las prácticas}

Es cierto que desde una vitalidad indudablemente inconformista el tándem arte/ biotecnología ha articulado, algunas veces, miradas poco condescendientes. Profundamente surcado por ciertos impulsos críticos y, en cierta medida, desestabilizadores, el duplo en cuestión por momentos ha sido objeto de exploración de movimientos activistas. A este respecto, Joseph Dumit (2008) señala:

Al mismo tiempo, artistas, activistas y escritores confrontan el problema de la política interrogando a la biología. Los bioartistas articulan vida para hacer de la biología un objeto de reconocimiento e interés para todos: los activistas reconfiguran ejes de autoridad, conocimiento y regulación para cambiar cómo opera el interés por la vida. ${ }^{\text {iv }}$

19 Cierto es que desde el aparato de pensamiento poshumano se ha venido poniendo en jaque gran parte de los presupuestos que ponen al hombre en el sitial de potestad, contraponiendo a esta visión, surcada por postulados de la modernidad, conceptos tales como los de inter-especialidad e hibridez. Sin dudas, es en estas zonas de detonación de 
los paradigmas antropocentristas donde se habilitan territorios para re-pensar e imaginar nuevos escenarios de activaciones creativas.

Muchos de los trabajos de Ana Laura Cantera plantean la emergencia de este tipo de miradas al poner en juego el concepto de "co-creación": un proceso centrado en la horizontalidad, en el que la impredecibilidad de la obra destierra toda alternativa de control por parte del sujeto creador, haciendo que la dinámica repose fuertemente en el factor tiempo como variable de cambio y transformación. Cantera trabaja con fenómenos vitales para el equilibrio de la biosfera pero que escapan a la visibilidad humana: la energía vegetal, el potencial de la tierra como sustrato, el accionar de las bacterias, la actividad de los procesos de oxidación, etc. Todos estos fenómenos son caracterizados por la artista como "miniaturas" que son parte de "mundos mínimos". La tecnología logra así liberarse de un tipo de estrategia que muchas veces suele adoptar sesgos reduccionistas (en la tradición más habitual de la creación tecnológica) y logra funcionar, en cambio, como un agente de transducción de los procesos, integrándose a los propios devenires biológicos y escapando a todo atisbo cientificista. Las creaciones tecnológicas de las últimas décadas, han basado sus lógicas en conceptos tales como los de interfaz, código, dispositivo, etc. No hay en ellas un "más-acá" de cierta ontología y teleología tecnológica que reduce sus lógicas a funcionamientos basados en dinámicas de interfaz, en operaciones algorítmicas o en mediaciones de índole diversas. Si hasta no hace mucho la noción de "interactividad" ocupó un lugar de privilegio en la escena siempre cambiante de los usos artísticos de la tecnología (y cuyo relevo lo ocupan hoy la visualización de datos o los revivals de escenarios virtuales), lo que importa es notar que en estas alternancias de tropos tecnológicos subyace una primacía de la impronta de naturaleza tecnológica. Su materialidad ejerce una especie de tiranía y contamina sus sentidos. Desde una lógica gestáltica perceptual, la tecnología lleva a cabo la "ley de cierre": es el eslabón que otorga un sentido último, que hace que el caos devenga orden. En esta operación podría llegar a advertirse, en última instancia, un gesto con tintes reduccionistas. Aplaca todo aquello que pueda tomar desvíos. A pesar de que muchas obras tecnológicas pretenden desplegar dinámicas de no-linealidad, multi-dimensionalidad, dispersión e incertezas, todo finalmente se sujeta a una lógica de funcionamiento que somete a las formas y a los lenguajes a un conglomerado asible. Si bien hay artistas que, aun desde discursividades forjadas a la luz de los lenguajes tecnológicos, han gravitado en los confines de esta tecno-supremacía del sustrato, lo que ocupa una centralidad clara en la escena son aquellos trabajos en los que la propia materialidad y retórica tecnológica instauran la verticalidad de los paradigmas.

21 Flujos en retorno, sin embargo, parece ir contra la corriente. Pone en escena enlaces, vínculos e intersecciones de estados por medio de elementos que se encuentran en relación de paridad, en un conjunto a-jerárquico. Cantera fabrica ladrillos con materia orgánica, los ubica en entornos naturales y, más tarde, éstos son elegidos como hábitat por diferentes colonias de bacterias y microorganismos. Intervenidos por celdas microbianas , cuya irrigación es posible gracias a un Tornillo de Arquímedes y diseñados en parte con materiales del medio natural contiguo, generan, como resultado de las acciones y funciones de los diferentes elementos encabalgados, un circuito de retroalimentación. Cantidad de energía recolectada, frecuencia de giro, producción de energía, caudal de riego, acción de los microorganismos, desintegración de los ladrillos articulan una dinámica cíclica, profundamente embebida en el entorno natural. 
Fig. 1. Flujos en retorno

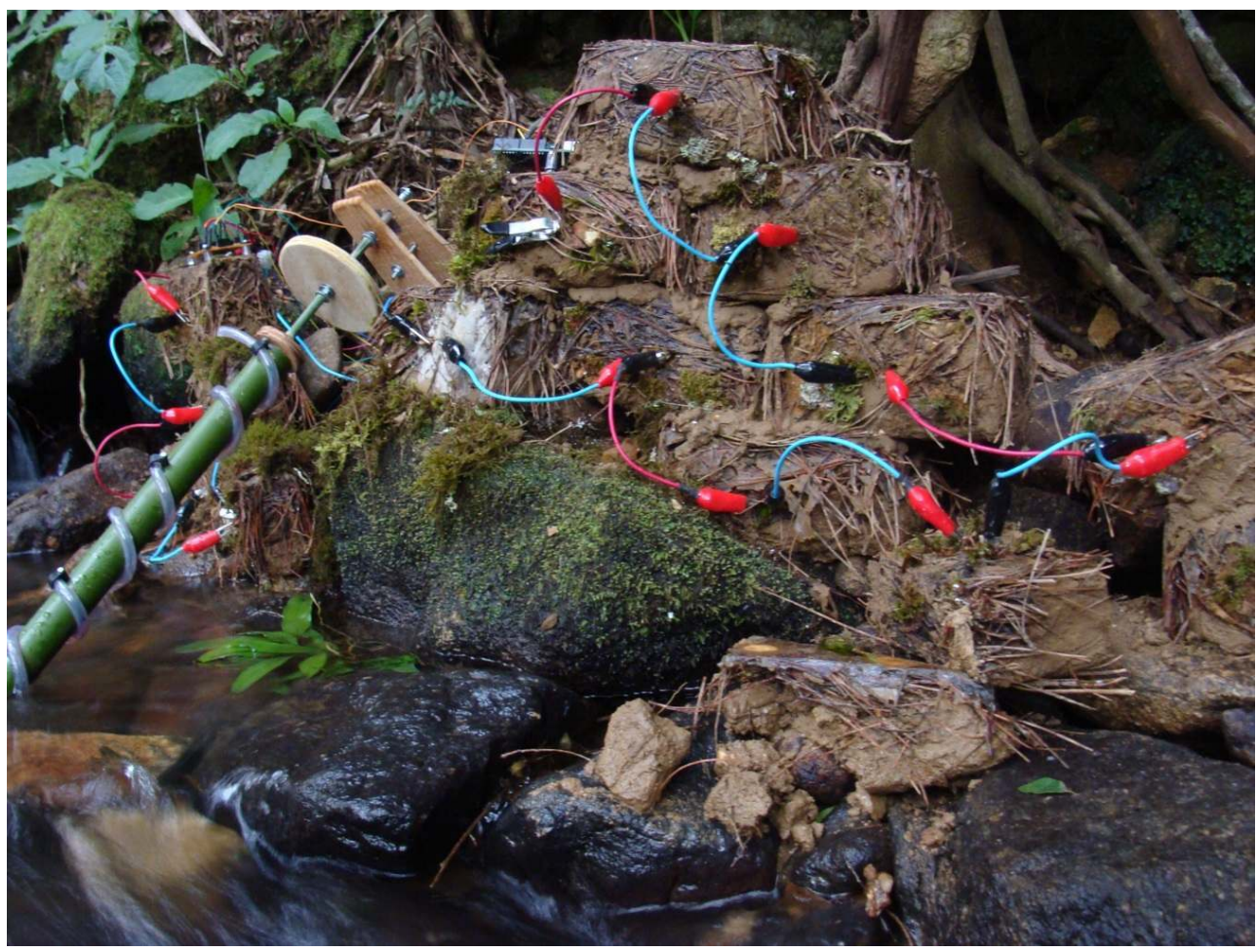

2013

22 El crecimiento de las bacterias produce un incremento energético hasta un cierto rango máximo, ya que la multiplicación progresiva de las colonias genera a su vez el deterioro de los ladrillos y, por ende, la destrucción de los mismos, el descenso de la actividad electroquímica y el consecuente declive de la producción energética.

Lo que interesa destacar es que en el trabajo de Cantera, lo tecnológico pierde su carácter de interfaz. En esta suerte de juegos y diálogos entre elementos diversos, lo que opera como instancia de intermediación es la propia naturaleza. Interrogada al respecto, Cantera respondió: "en mi trabajo, la naturaleza es la interfaz" v. Así, la naturaleza sería una suerte de superficie de intermediación -en términos de Cantera- o, una plataforma posibilitadora de ciclos de retroalimentación, en "disponibilidad" -parafraseando a la artista- para generar procesos inter-especies e inter-objetos de inter-modificación. 
Fig. 2. Flujos en retorno

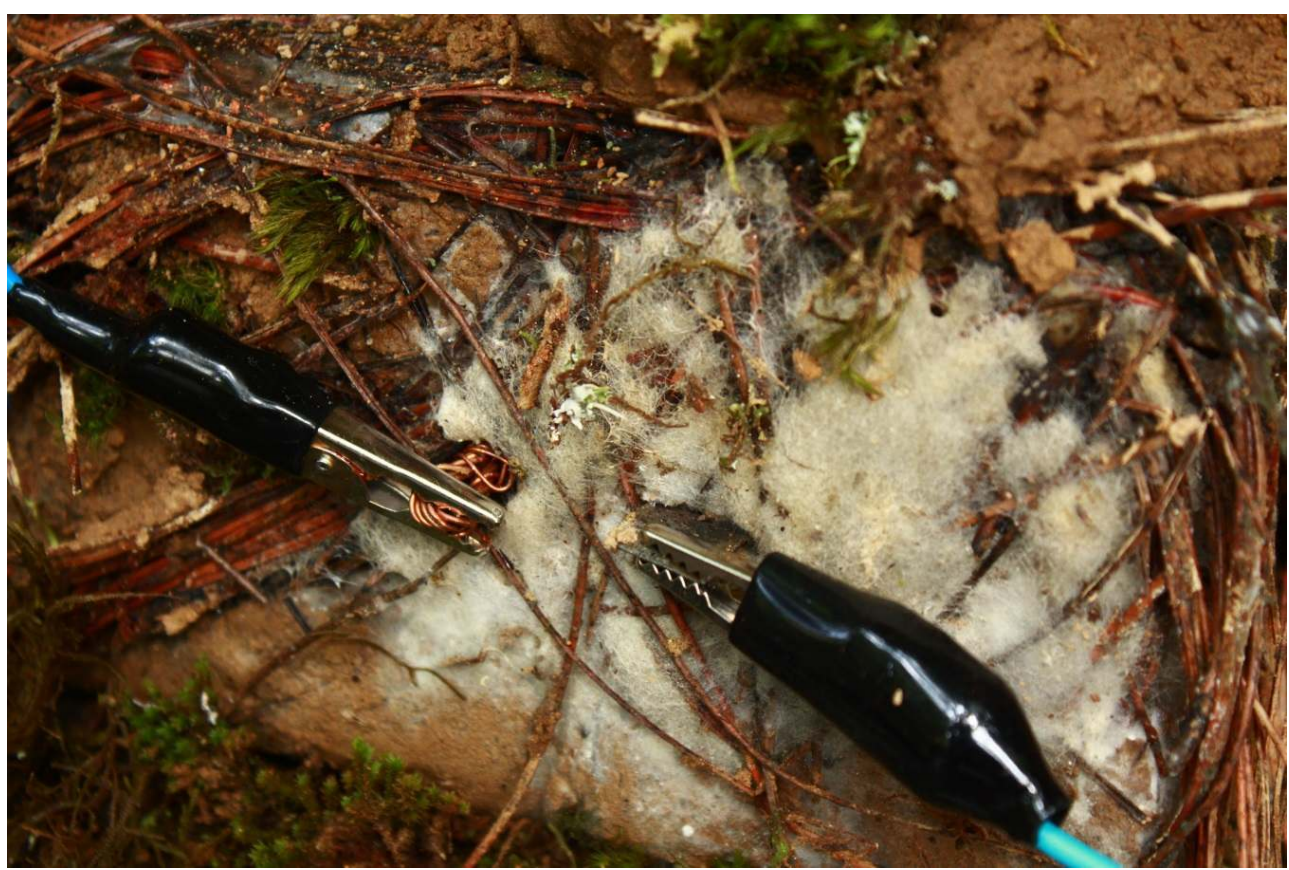

2013. Detalle de la descomposición de los ladrillos

\section{Más allá de la razón instrumental}

“[...] es el camino de la naturaleza que hace que el hombre pase de la minoría de edad a la madurez" (KUSCH 2000, vol. 4, 482)

Para el filósofo argentino Rodolfo Kusch, la técnica occidental y la mirada que la misma prevé se sostienen sobre la lógica de lo esperable, lo asible, lo concebible. Más allá de estos límites, sobreviene el temor por el derrumbe de un saber orientado hacia la idea de "progreso", porque, para Kusch, la "técnica implica esencialmente una puesta en práctica de lo que se espera...” (KUSCH 2000, vol. 2: 10).

Lo que propone Kusch, en definitiva, es pensar otros derroteros epistemológicos situados en el ámbito del continente mestizo para trascender ese saber instrumental, ese saber de la ciencia moderna, netamente occidocéntrica. La condición mestiza reside en la amalgama de un saber adquirido y otro que proviene de la dimensión emocional y vegetal. Es esta dualidad óntica (civilización/barbarie) la que modela una simultaneidad vivencial para el autor: "entre lo indeterminado y lo definido, entre el sentimiento de privación y el de plenitud" (Kusch, 2000, vol. 2: 97 y 99). O, también, en el sentido del concepto de ch'ixi que trabaja Silvia Rivera Cusicanqui (2010), el cual da cuenta de lo abigarrado y de la coexistencia de múltiples diferencias que no se funden, sino que antagonizan o se complementan.

Nos interesa solamente hacer ver aquí que en todo tiempo el americano es víctima del vegetal, por un lado, y de la idea, por el otro, y que no concilia su escisión, si no es haciéndose mentalmente mestizo. De ello se encarga el vegetal que nunca se relega, sino que abarca a todo el hombre y a todas sus manifestaciones. Selva, árboles, piedras, animales, son los medios naturales de fijación y expresión. La naturaleza en su formalidad, expresa el linaje. Ella comparte, plenamente “consciente”, la visión y la posesión de las cosas. (KUSCH 2000: vol. 4, 33-34) 

abordar estas prácticas locales en las que la mirada de los artistas se entreteje con la naturaleza, por fuera de las fronteras (no solamente físicas sino también epistémicas) del laboratorio, en tanto topos paradigmático de la ciencia moderna. Las dinámicas de los trabajos aludidos adoptan formas distintivas, que privilegian la propia autonomía de las partes en el marco de un todo integrado, donde cada una de las entidades es de naturaleza diversa pero en relación de paridad (hombres, plantas, dispositivos, animales, comunidad, etc.). Sobre todo, delinean otros puntos de vista en relación al entorno: superan la exterioridad de la mirada humanocéntrica para plantear un "estar-siendo" en términos kuscheanos: un estar situado en la indeterminación, una humanidad dinámica en un acontecer empírico y particular. articulan prácticas tecnobiológicas cuando dice que lo que hacen es tratar "constantemente de hablar de su condición, de su situación y su pensamiento" para entender a la naturaleza "en su territorio". El colectivo Electrobiota (del que forma parte Munguía junto a Guadalupe Chávez), ha venido indagando acerca de esta vitalidad territorial, embebiéndose en el propio hábitat. A uno de sus trabajos, RizosferaFM, lo definen como un espacio de experimentación y exploración. Consistió en una instalación e intervención sonora donde plantearon la apropiación y la resignificación de los medios masivos de comunicación, a modo de extensiones y redes híbridas entre humanos y otras especies. Inspirado en las infinitas formas de vida que habitan la rizosfera, sus formas de entender y relacionarse, la integración de elementos biológicos, la comunicación remota, la apropiación de tecnologías, los flujos sonoros y lumínicos, las frecuencias, los ritmos y sintonías, plantearon la hibridación de sistemas como un mecanismo y proceso de cocreación sensible a la mirada e interpretación por parte de aquellos micro-hábitats donde infinitos seres cohabitan, interactúan, construyen y se expresan.

Rizosfera FM centra su mirada en las frecuencias sutiles, señales emisoras y portadoras de información pertenecientes a un microcosmo conformado por una infinidad de formas de vida que moran bajo la tierra. Este entramado orgánico y vivo fue concebido como un territorio sensible, dinámico y complejo en el que las raíces de las plantas, los hongos, las bacterias, los minerales y el agua conviven bajo el principio de autonomía operacional, interactuando íntimamente y generando distintos procesos bio-geoquímicos que ayudan a mantener el balance de los suelos.

Tomaron como primer lugar de exploración las cercanías de la estación ferroviaria de Caseros y el Museo de Artes Visuales de la Universidad Nacional de Tres de Febrero (MUNTREF), Provincia de Buenos Aires. A partir del desarrollo y la construcción de una serie de biosensores DIY midieron la actividad de la rizosfera de los árboles de las afueras de la estación de tren, amplificando sus señales y transformándolas en sonido analógico. Estas señales fueron retransmitidas por canales locales de radio, que podían ser sintonizados y escuchados en tiempo real haciendo uso de radios comunes por parte del público. Para el colectivo Electrobiota

"La idea de apropiarnos y de hackear las redes de comunicación masivas funcionó como posibles caminos de acción y concientización sobre nuestra relación con la naturaleza. Estas acciones nos inspiran a imaginar la posibilidad de "construir" conocimiento desde una búsqueda transversal. Donde la emergencia y reapropiación de procesos, metodologías, herramientas y paradigmas tecnocientíficos permiten la construcción de nuevos lenguajes de reflexión y mecanismos estéticos, cognitivos y conceptuales sobre nuestro hacer artístico, y también nuevas 
responsabilidades como constructores y agentes activos sociales, políticos y culturales" vi.

Fig. 3. RizosferaFM

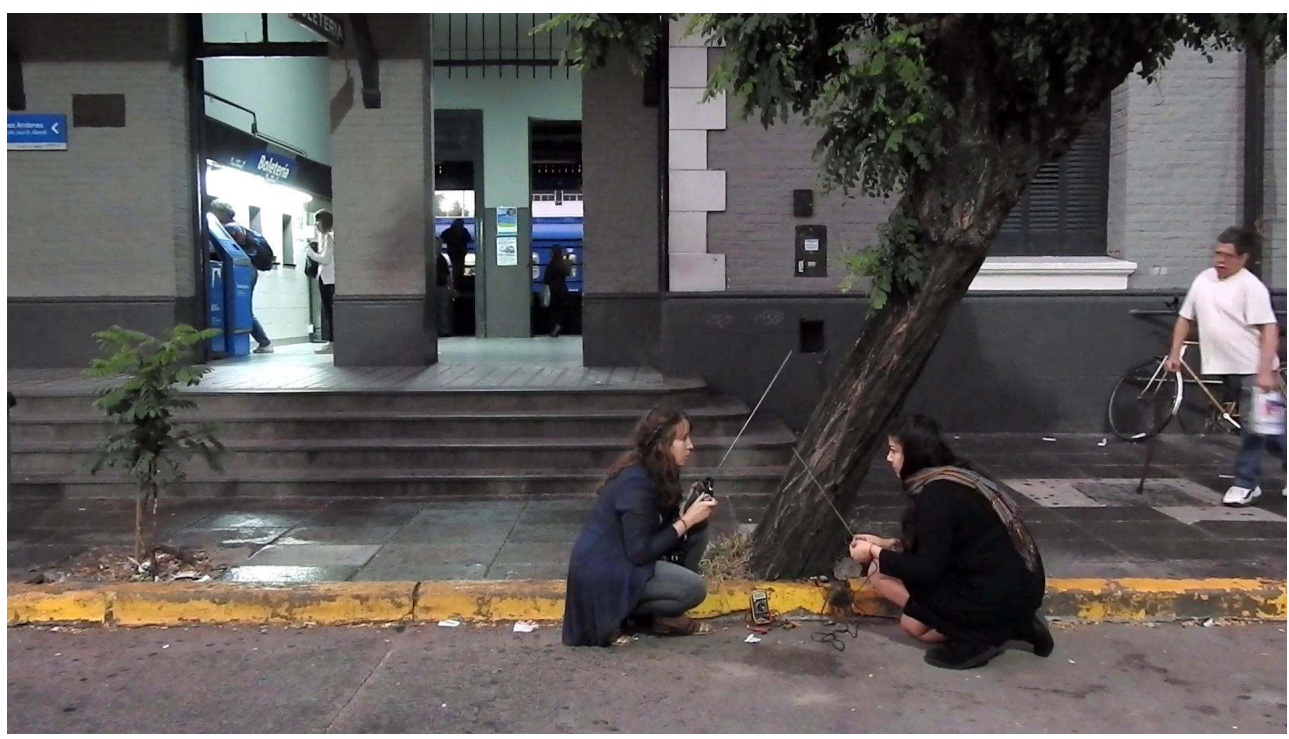

2016 el mundo humano y el animal y afirma:

"Entre el árbol y el hombre, no dista más que una diversa aplicación de una energía original. En el vegetal, la energía se da al principio, se define como savia, pez, alga, o árbol; pero en el hombre está al final, sale de sus manos para crear un mundo fijo que, si bien llama espíritu, no escapa a la índole del vegetal" (KUSCH 2000: 34- 35).

Hay en este trabajo de Electrobiota un profundo embebimiento entre intimidades biológicas: la de la dimensión vegetal y su entretejido informacional y la del gesto creador profundamente imbricado en el espectro biológico:

"Nos gusta imaginar la posibilidad de construir interfaces y protocolos comunicacionales en un mismo plano de realidad en el que materia y espíritu pueden encontrarse y comunicarse no como realidades apartes, sino como sistemas interconectados e interdependientes". vii

Se trata así de abrir senderos hacia los mundos biológicos interconectados e interdependientes, siendo las artistas parte integrante de esta profunda interrelación. Un mundo vibrante en el que el sujeto creador se agita a su propio ritmo, manifestando su naturaleza mestiza: la esfera de la comunicación tecnológica embutida en los sistemas vivos. La predecibilidad técnica cohabita y es desbaratada, al mismo tiempo, por las transformaciones biológicas y orgánicas de este microhábitat en el que los seres vivos que lo conforman emiten sus propias señales. Microhábitat del que también las artistas eligen deliberadamente formar parte.

Guadalupe Chávez, la otra integrante de Electrobiota, imagina un corpus -tal vez cercanamente al concepto de Nancy viii. Corpus como marco de una "co-esencialidad" de "intercambios energéticos compartidos, que nos conforman como una organización viva" ix. Para la artista:

"A partir de co-crear con el reino vegetal, desde sus formas, colores, texturas y frecuencias, busco una práctica que me permita sentir que el arte no es sólo una 
mera construcción humana, sino que soy partícipe consciente de aquello insondable, invisible e intangible que se manifiesta en la naturaleza para obtener un cuerpo." $\times$

Las prácticas de este colectivo, al igual que las de Cantera, operan desde el "estar-siendo" del que habla Kusch. Logran trascender el trauma del usuario de una tecnología que se funda en plataformas epistemológicas que sustentan una centralidad científica y técnica, y repelen la seducción de la hegemonía bioartística en cuanto a estrategias artísticas fundadas en el trabajo con materiales biológicos desde los paradigmas de la ciencia moderna. Las prácticas referidas son prácticas situadas, que se incrustan en el territorio. Munguía lo expresa cabalmente cuando dice:

"Entender la vida es la manera de trabajar con la naturaleza porque hay que entenderla en el territorio. La naturaleza no como una proteína, no como un aminoácido, no como un ADN sino como un gran sistema y así descentralizar el lenguaje humano para permitir otros lenguajes, otras semánticas, otras dialécticas y descomponer el pensamiento antropocentrista. Uno no vive en el vacío, vive en el territorio. Hay que descentralizar las cajas del conocimiento. En Latinoamérica, el artista vuelca lo vivo al territorio". xi

Fig. 4. RizosferaFM

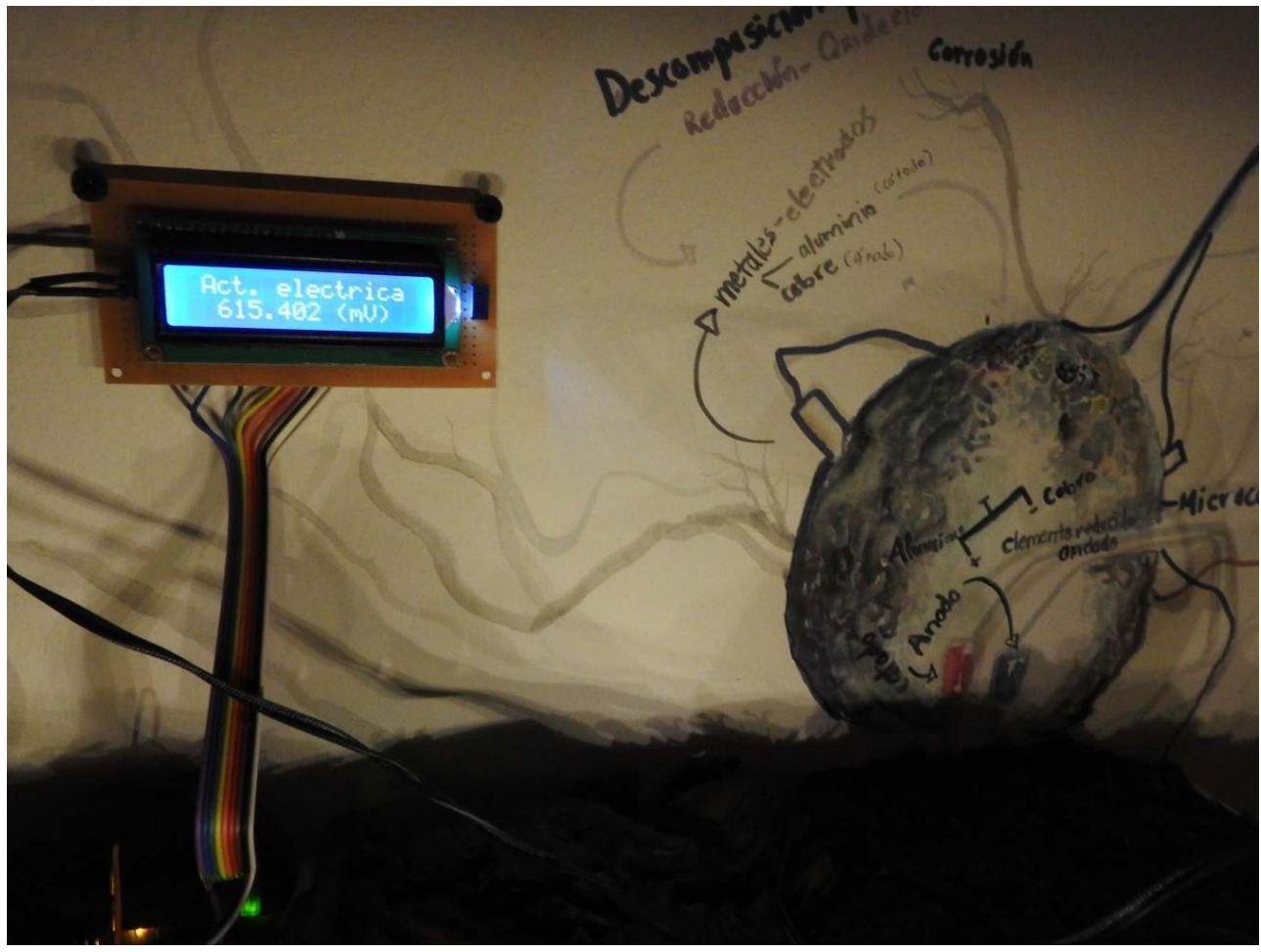

2016. Detalle

Pareciera entonces que en estos trabajos y en los de tantos otros artistas latinoamericanos ${ }^{\mathrm{xii}}$, operando desde un "estar-siendo" en la naturaleza y abandonando los presupuestos del bioarte, delinean otros escenarios de acción/creación. Frente a la exterioridad del artista-biólogo e incluso, frente a la postura crítica de los bio-activistas (particularmente en relación a los procesos de manipulación de la ciencia), estas estrategias dan cuenta de otra dimensión: generan miradas propias que trascienden la razón instrumental que sostiene a la tecnociencia; generan y articulan procesos desde un escenario mestizo que se apropia de "lo moderno" tecnológico y lo transforma en 
dispositivos embebidos y situados en el propio contexto natural, activando relaciones de diálogo y de profunda co-habitación. Así, la propia naturaleza -citando una vez más a Cantera- deviene la propia interfaz.

\section{A modo de cierre}

Los dos casos aludidos -la obra de Ana Laura Cantera y la del colectivo Electrobiotadesertan del espectro tecnocientífico al no quedar entrampadas en la “jemmybutonización" de las prácticas. Plantean otros derroteros que se fundan en un estar-siendo con la naturaleza y es a esta imbricación que las prácticas tecnológicas se adhieren para que sus procesos discurran con aquellos de la naturaleza. Más allá de toda aproximación ontológica en lo que respecta a una cierta noción de "latinoamericanidad", lo que me interesa es poner el acento y visibilizar experiencias concretas que parten de una radicación y compenetración territorial, rompiendo con paradigmas normalizados y hegemónicos. Son prácticas que ponen en juego una cierta fenomenología del trinomio arte/naturaleza/tecnología y que parecen sugerirnos que la incorporación de lo biológico a la obra puede transitar caminos diferentes a los de la biomedialidad, dejando paso a experiencias que, en definitiva, articulan escenarios de vida.

\section{BIBLIOGRAFÍA}

BUTLER, Judith. Lenguaje, poder e identidad. Madrid: Síntesis, 2004.

DA COSTA, B.; PHILIP, K. (comp.). Tactical Biopolitics. Art, Activism, and Technoscience. Cambridge: MIT Press, 2008.

DARWIN, Charles. Diario del viaje de un naturalista alrededor del mundo. Madrid: Espasa-Calpe, 1999.

KUSCH, Rodolfo. Obras Completas. Santa Fe: Fundación Ross, 2000.

LÓPEZ DEL RINCÓN, Daniel. Bioarte: arte y vida en la era de la Biotecnología. Madrid: Akal, 2015.

MIGNOLO, Walter. "Globalization and the Geo-Politics of Knowledge: The role of the Humanities in the Corporate University". Nepantla: Views from the South. 4

NANCY, Jean-Luc. Corpus. Madrid: Arena Libros, 2003.

RIVERA CUSICANQUI, Silvia. Ch'ixinakax utxiwa Una reflexión sobre prácticas y discursos descolonizadores. Buenos Aires: Tinta Limón, 2010.

WALLERSTEIN, Immanuel. El moderno sistema mundial, tomo I. México: Siglo XXI Editores, 1979. 


\section{NOTAS FINALES}

i. "El trauma social toma la forma no de una estructura que se repite mecánicamente sino más bien de una subyugación continua, un volver a poner en el escenario la injuria a través de signos que ocultan y al mismo tiempo repiten la escena". BUTLER, 2004, 66.

ii. Noción mucho más afín a una idea de progreso histórico teñido de un sesgo evolutivo, propio de una mirada temporal, asentada en la unilinealidad distintiva de la matriz ideológica de la modernidad.

iii. "There is quite simply no space outside the laboratory, no space that isn't kin to a lab, and no part of the lab time isn't a site of social, political, and artistic regulation and invention" (traducción personal). DUMIT, J. "Foreword: Biological Feedback". In DA COSTA, B.; PHILIP, K. (comp.). Tactical Biopolitics. Art, Activism, and Technoscience. Cambridge: MIT Press, 2008.

iv. "At the same time, artists, activists, and writers confront the problem of politics requiring biology. Bioartists articulate life to make biology an object of recognition and concern for all; activists reconfigure lines of authority, knowledge, and regulation to change how concern about life operates" (traducción personal). Ibid., xii.

v. Entrevista a Ana Laura Cantera realizada en marzo 2015

vi. Disponible en https://colectivoelectrobiota.wordpress.com/proyectos/rizosfera-fm/ (último acceso: septiembre 2017)

vii. Ibid.

viii. “cuerpo es la unidad de un ser fuera de sí” (NANCY 2003: 98)

ix. Entrevista a Guadalupe Chávez realizada en agosto 2017.

x. Entrevista a Guadalupe Chávez realizada en agosto 2017.

xi. Entrevista a Gabriela Munguía realizada en agosto 2017.

xii. Gilberto Esparza, Arcángelo Constantini, Marcela Armas (México), Guto Nóbrega (Brasil), Paul Rosero (Ecuador), por citar sólo a algunos.

\section{RESÚMENES}

El diálogo arte-tecnología en América Latina pone en foco litigios recurrentes: ¿tecnologías sustentadas por los discursos legitimantes de la modernidad o paradigmas diferentes y periféricos en la asunción e ideación de tecnologías en el contexto del arte? ¿Qué sucede con las prácticas que incorporan elementos biológicos, habitualmente uniformizadas bajo la categoría de "bioarte"?

Las prácticas artísticas tecnológicas en Argentina en los últimos diez años alumbran zonas de pensamiento y praxis que ameritan ser revisadas: el diálogo arte/naturaleza desde perspectivas no-antropocéntricas, la configuración de discursos en los que subyacen representaciones, miradas y prácticas que se apartan de cánones normalizados $\mathrm{y}$, por último, operaciones disruptivas en lo que respecta a los algo usuales criterios de funcionalidad, utilitarismo y efectismo tecnológico.

Le dialogue art-technologie en Amérique latine met en lumière des contentieux récurrents: les technologies sont portées par des discours légitimateurs de la modernité? ou représentent-elles 
des paradigmes différents et périphériques dans la prise en charge et l'idéation des technologies dans le contexte de l'art? Que se passe-t-il avec les pratiques qui intègrent des éléments biologiques, généralement normalisés dans la catégorie «bioart»?

Ainsi les pratiques artistiques technologiques en Argentine au cours des dix dernières années éclairent des domaines de pensée et de pratique qui méritent d'être révisés. Par exemple le dialogue art/nature à partir de perspectives non anthropocentriques, la configuration des discours dans lesquels les représentations, les opinions et les pratiques s'éloignent des canons standardisés et, enfin, les opérations disruptives par rapport aux critères habituels de fonctionnalité, d'utilitarisme et d'efficacité technologique.

\section{ÍNDICE}

Palabras claves: naturaleza, tecnología, decolonialidad, co-creación, territorio

Mots-clés: nature, technologie, décolonialité, co-création, territoire

\section{AUTOR}

\section{MARIELA YEREGUI}

Universidad Nacional de Tres de Febrero - myeregui(at)untref.edu.ar 